14. Linnaeus C. Species Plantarum, 1753, Imprensis Laurentii Salvii, Holmiae, 2 vols. Vol. 1: P. 1-560; Vol. 2: P. 561-1200.

15. Невский С.A. Orchidaceae Lindl // Флора СССР. М.; Л.: АН СССР, 1935. Т. 4. С. 589-730.

16. Иванова Е.В. Сем. Orchidaceae // Флора Сибири. Araceae-Orchidaceae. Новосибирск: Наука, 1987. T. 4. C. $125-145$.

17. Красноборов И.М., Крапивкина Э.Д., Ломоносова М.Н. и др. Определитель растений Кемеровской области. Новосибирск: Издательство СО РАН, 2001. $477 \mathrm{c}$.

18. Красноборов И.М., Ломоносова М.Н., Шауло Д.Н. и др. Определитель растений Алтайского края. Новосибирск: Издательство СО РАН, филиал «Гео», 2003. $634 \mathrm{c}$.
19. Пяк А.И. Сем. Орхидные - Orhidaceae // Определитель растений Томской области. Томск: Издательство Томского университета, 2014. С. 342-351.

20. Swsrtz O. Orchidernes, 1800, Kongl. Vetenskaps Academiens Nya Handlingarpp. Vol. 21. P. 202-254.

21. Доронькин В.М. Сем. Orchidaceae // Флора Сибири. Новосибирск: Наука, 2003. Т. 14. С. 35-37.

22. Вахрамеева М.Г., Варлыгина Т.И., Татаренко И.В. Орхидные России (биология, экология и охрана). М.: Товарищество научных издательств КМК, 2014. $437 \mathrm{c}$.

Исследования выполнены в рамках проекта VI.52.1.3. «Выявление путей адаптации растений к контрастным условиям обитания на популяционном и организменном уровнях". Номер госрегистрации АAAA-A17-117012610053-9.

\title{
THE GENUS CYPRIPEDIUM L. IN THE UNIQUE HABITAT OF ORCHIDS IN THE NOVOSIBIRSK REGION
}

(C) 2018

Gerasimovich Lyudmila Vladimirovna, candidate of biological sciences, junior researcher of Ornamental Plants Introduction Laboratory

Central Siberian Botanical Garden of Siberian Branch of Russian Academy of Sciences (Novosibirsk, Russian Federation)

Abstract. This paper provides information about the unique habitat, where 13 species of orchids of the genera Dactylorhiza Nevski, Epipactis Zinn, Gymnadenia R. Br., Herminium R. Br., Orchis L., Platanthera L.C.M. Rich., Cypripedium L. grow in Iskitim District of the Novosibirsk Region. A morphological description of three kinds of shoes is given, including a new for the Novosibirsk Region species Cypripedium $\times$ ventricosum Sw., which is proposed to be included in the Red Book of the Novosibirsk Region. The investigated community of shoes is located in a birch-high-herbage forest, in the Koyniha river basin. Comparison of the characteristics of the vegetative and generative organs Cypripedium x ventricosum Sw., Cypripedium calceolus $\mathrm{L}$. and Cypripedium macranthon Sw, described as a result of monitoring, is compared with literary data. It was shown that all parameters of C. calceolus, except for the bract length (greater than average), are included in the described range. In the studied habitat, most of the parameters of $C$. macranthon and $C$. $\times$ ventricosum (the length and width of the bract, the length and width of the lateral leaf of the perianth of the inner circle) have higher values. It allows us to conclude that the eco-cenotic conditions of the studied habitat are most favorable for C. macranthon and $C . \times$ ventricosum. Cenopopulations of all three species exist for a fairly long period and are in their real optimum.

Keywords: Orchidaceae Juss. family; Cypripedium x ventricosum Sw.; Cypripedium calceolus L.; Cypripedium macranthon Sw.; new kind for Novosibirsk Region; Iskitimsky District; comparative morphology; monitoring; protection of rare species; Red Book of Novosibirsk Region.

УДК 631.2/3.03:631. 531.06

DOI 10.24411/2309-4370-2018-14105

Статья поступила в редакцию 03.06.2018

\section{РЕПРОДУКТИВНЫЕ ОСОБЕННОСТИ FESTUCA RUBRA L. В РАЗНЫХ ЭКОЛОГИЧЕСКИХ УСЛОВИЯХ}

Зуева Галина Александровна, кандидат биологических наук, старший научный сотрудник лаборатории интродукции декоративных растений Центральный сибирский ботанический сад СО РАН (2. Новосибирск, Российская Федерация) Хусаинова Ирина Викторовна, научный сотрудник лаборатории интродукции Институт ботаники и фитоинтродукичи (2. Алматы, Республика Казахстан)

Аннотация. В работе представлены сравнительные результаты изучения семенной продуктивности Festuca rubra L. в условиях Сибири и Казахстана. Рассмотрено влияние экологических условий на органообразовательный процесс вида. Выявлены особенности роста и развития растений при разных сроках высева в разных экологических условиях. В первый год вегетации растения во всех вариантах проходят две фенологические фазы - всходы и кущение. Разные сроки посева вносят существенные изменения в репродуктивную способность растений. У растений весеннего посева верхушечная меристема в конце вегетационного периода соответствует IV этапу органогенеза. Весной следующего года побеги 2-го, 3-го и 4-го порядков тоже переходят в генеративное развитие. Определен оптимальный способ выращивания Festuca rubra с максимальными показателями семенной продуктивности. Выяснено, что при весеннем посеве максимальный урожай семян (до 48 г $\left./ \mathrm{M}^{2}\right)$ можно получить на третий год жизни злака. На четвертый год наблюдается небольшое сни- 


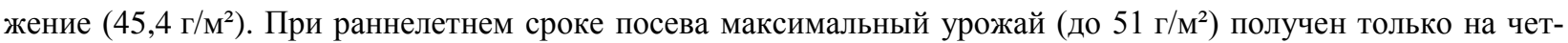
вертый год жизни растений и наблюдается дальнейшее снижение. При осеннем посеве первое плодоношение злака приходится только на 3-й год жизни и выражается в максимальном количестве побегов и урожае семян $\left(68\right.$ г $\left.\mathrm{M}^{2}\right)$. Дальнейшее резкое снижение таких показателей, как генеративные побеги и урожай, говорит о нецелесообразности сохранения семенников.

Ключевые слова: Festuca rubra; газонное растение; эколого-биологические особенности; климатические условия; лабораторная и полевая всхожесть; репродуктивная способность; органогенез; семенная продуктивность; урожай; экологические условия; индукция цветения; семеноводство; способы выращивания; г. Новосибирск; г. Алматы.

\section{Введение}

Festuca rubra L. - обладая широкой географической амплитудой и большой пластичностью, многолетний злак представлен огромным разнообразием популяций и форм. Вид распространен почти по всей Европе, на Кавказе, Сибири, Дальнем Востоке, Внетропической Азии, Северной Америки. По определению Н.Н. Цвелева [1], он имеет биполярный внетропический ареал.

В условиях Южной Сибири и Юго-Востока Казахстана F. rubra отличается высокой зимостойкостью, переносит поздние весенние и ранние осенние заморозки, проявляет высокую устойчивость к грибным заболеваниям [2].

Разрабатывая основные приемы использования F. rubra в культуре для задернения почвы, нельзя обойти вопросы по изучению эколого-биологических особенностей. В травосмесях этот злак занимает доминирующее положение с первого года жизни, влияет на формирование травостоя, его устойчивость и декоративность.

В связи с масштабами градостроительства есть огромный спрос на семенной материал, а значит, развитие семеноводства дернообразующих трав очень актуально [3; 4]. Так как вегетативное развитие является основой для генеративного развития, изучение соотношения побегов дает нам возможность сделать прогноз по семенной продуктивности [5; 6].

Целью нашей работы являлось изучение семенной продуктивности дернообразующего злака Festuca rubra, создание семенного фонда местной репродукции и использование семян для создания дерновых покрытий на территории Сибири (Новосибирск) и Казахстана (Алматы).

\section{Материал и методы исследований}

Районы, где были заложены эксперименты, имеют резко континентальный и континентальный климат, расположены на различных широтных координатах.

В первом районе объектом изучения стал образец Festuca rubra - К-0026 из природной флоры (верховья р. Текес, горы, 2500 м над уровнем моря), найденный в высокогорной области (Вариант А1). Полевой опыт заложен осенью (10 сентября) в Талгарском районе (Алматы, Казахстан). Район подгорно-равнинный. Весной, с конца 2-й и в начале 3-й декады марта, наблюдается устойчивый переход температуры воздуха через $0^{\circ} \mathrm{C}$. Осенью - в конце 1 й начале 2-й декады ноября. Безморозный период в среднем составляет 140-170 дней. Осадков за год выпадает 350-600 мм, за вегетационный период 120300 мм. Сумма положительных температур составляет $3450-3750^{\circ} \mathrm{C}$.

Во втором районе объектом исследования была местная дикорастущая форма F. rubra, прошедшая первичный отбор как перспективный дернообразующий злак. Два опытных посева были проведены на экспериментальном участке (Новосибирск, Россия). Первый посев - весенний (10 мая) (Вариант Н1), второй - раннелетний (10 июня) (Вариант Н2). Климат Новосибирской области континентальный, Средняя температура вегетационного $16-19^{\circ} \mathrm{C}$. Сумма положительных температур в среднем составляет $1920^{\circ} \mathrm{C}$. Среднегодовое количество осадков составляет 442 мм. За период исследования наблюдается повышение среднесуточных температур воздуха по сравнению со среднемноголетними. В весенние месяцы $\left(+2^{\circ} \mathrm{C} \ldots\right.$ $\left.\ldots+4^{\circ} \mathrm{C}\right)$, в первой половине лета $\left(+17^{\circ} \mathrm{C} \ldots+18^{\circ} \mathrm{C}\right)$ и октября $\left(+1^{\circ} \mathrm{C} \ldots+4^{\circ} \mathrm{C}\right)$, в остальной период колебались в пределах среднемноголетних значений, что характерно для потепления климата региона [7].

Наблюдения за фазами развития растений проводили по методике для ботанических садов (1975), с дополнениями для газонных растений [9-10]. Морфологический анализ для определения этапа органогенеза проводили по методике Ф.М. Куперман [11] и Е.И. Ржановой [12; 13].

Закладка семенных посевов - широкорядная, что обеспечивает возможность ухода и создает наилучшие условия светового режима для растений [14]. Для определения количества генеративных побегов и массы семян анализ проводился в генеративном состоянии по 10-ти растениям. Параметры снимались с 1 м.п. в рядовом посеве в 10-кратной повторности. Длину метелки, количество семяпочек и семян на побеге определяли на 30 растениях. Изучение семенной продуктивности поводили по методике Р.Е. Левиной [15].

Результаты исследований обрабатывали методом дисперсионного анализа [16]. Статистическую обработку данных проводили по методике анализа выборок с помощью приложения программы Excel 2010 [17]. Ошибка средней арифметической (число генеративных побегов, шт./M²) подсчитана на выборке $(\mathrm{V}=10)$. Сделана оценка достоверности средней арифметической с помощью критерия Стьюдента.

\section{Результаты исследований и их обсуждение}

Лабораторная всхожесть используемых семян в Новосибирске составила 95\%, семена дружно взошли уже на 8-й день. После посева на опытных участках в Варианте Н1 всходы появились на 14-й день, полевая всхожесть составила 45\%. В Варианте Н2 массовые всходы появились на 12-й день, всхожесть составила 42\%. В Алматинской области в Варианте A1 - на 12-й день с полевой всхожестью $76 \%$.

В первый год жизни у растений $F$. rubra во всех вариантах было отмечено две фенологические фазы - всходы и кущение. После появления на главном побеге 5-6 листьев, развиваются побеги второго порядка. В течение вегетации развиваются побеги 3-го и 4-го порядка. 
Зуева Г.А., Хусаинова И.В.

На 2-й год жизни перезимовавшие вегетативные побеги 2-го, 3-го и частично 4-го порядков перешли к генеративному развитию и плодоносили. Отмечено сильное варьирование семенной продуктивности метелок по годам. Росту семенной продуктивности способствует влажность почвы и воздуха.
При весеннем посеве максимальное количество генеративных побегов (1447 шт./ $\left.\mathbf{M}^{2}\right)$ и урожай семян $\left(48 \Gamma / \mathbf{M}^{2}\right)$ зафиксирован на второй год плодоношения. При раннелетнем посеве - на третий год (1236 шт./ $\left.\mathbf{M}^{2}\right)$ и 51 г/м $\mathbf{M}^{2}$ соответственно) (табл. 1). Снижение реальной семенной продуктивности наблюдается в Варианте Н1 с 4-го года жизни растений, в Варианте Н2 с 5-го.

Таблица 1 - Семенная продуктивность и урожай Festuca rubra

\begin{tabular}{|c|c|c|c|c|c|c|c|c|}
\hline \multirow{2}{*}{$\begin{array}{c}\text { Год } \\
\text { жиз- } \\
\text { ни }\end{array}$} & \multirow{2}{*}{$\begin{array}{c}\text { Количество } \\
\text { генеративных } \\
\text { побегов, шт./м² }\end{array}$} & \multirow[b]{2}{*}{$\mathrm{t}_{\text {факт }}$} & \multirow{2}{*}{$\begin{array}{c}\text { Длина } \\
\text { метелки, } \\
\text { см }\end{array}$} & \multicolumn{2}{|c|}{ Количество на побеге, шт. } & \multirow{2}{*}{$\begin{array}{l}\text { Коэффици- } \\
\text { ент продук- } \\
\text { тивности, \% }\end{array}$} & \multirow{2}{*}{ 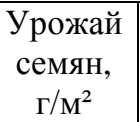 } & \multirow{2}{*}{$\begin{array}{c}\text { Мacca } \\
1000 \text { семян, } \\
\Gamma\end{array}$} \\
\hline & & & & семяпочек & семян & & & \\
\hline & & \multicolumn{7}{|c|}{ Весенний посев (Вариант Н1) } \\
\hline 2 & $305 \pm 10,0$ & 30,5 & 8,9 & 124 & 52 & 41 & 10,1 & 0,72 \\
\hline 3 & $1447 \pm 66,5$ & 21,8 & 12,6 & 173 & 92 & 53 & 48,0 & 0,84 \\
\hline 4 & $1300 \pm 70,2$ & 18,5 & 10,8 & 144 & 69 & 47 & 45,4 & 0,79 \\
\hline \multirow[t]{2}{*}{5} & $638 \pm 20,4$ & 31,2 & 7,3 & 78 & 33 & 42 & 33,2 & 0,69 \\
\hline & $\mathrm{t}_{05}$ & 2,2 & & & & & & \\
\hline & & \multicolumn{7}{|c|}{ Раннелетний посев (Вариант Н2) } \\
\hline 2 & $278 \pm 10,5$ & 26,5 & 10,5 & 108 & 44 & 40 & 8,2 & 0,65 \\
\hline 3 & $668 \pm 29,3$ & 22,7 & 12,2 & 146 & 68 & 46 & 20,4 & 0,58 \\
\hline 4 & $1236 \pm 46,9$ & 26,3 & 10,2 & 182 & 92 & 51 & 51 & 0,95 \\
\hline \multirow[t]{2}{*}{5} & $442 \pm 25,6$ & 17,2 & 9,6 & 120 & 54 & 45 & 36,4 & 0,63 \\
\hline & $\mathrm{t}_{05}$ & 2,2 & & & & & & \\
\hline & & \multicolumn{7}{|c|}{ Осенний посев (Вариант A1) } \\
\hline 3 & $1056 \pm 38,0$ & 27,1 & 10,6 & 108 & 61 & 56 & 68,8 & 0,80 \\
\hline 4 & $560 \pm 23,5$ & 15,1 & 8,8 & 155 & 55 & 37 & 8,4 & 0,76 \\
\hline 5 & $568 \pm 25,5$ & 10,6 & 10,6 & 163 & 69 & 42 & 10 & 0,87 \\
\hline \multirow[t]{2}{*}{6} & $424 \pm 22,0$ & 11,3 & 10,1 & 123 & 56 & 46 & 12,8 & 0,82 \\
\hline & $\mathrm{t}_{05}$ & 2,2 & & & & & & \\
\hline
\end{tabular}

Разные сроки посева вносят существенные изменения в репродуктивную способность растений. Морфологический анализ, проведенный в конце вегетационного периода первого года жизни растений, показал, что в Варианте Н1, на главном побеге развернулось 8-9 листьев, а верхушечная меристема соответствует IV этапу органогенеза. Развитие генеративной сферы началось с осени первого года (осенний тип генеративных побегов), весной следующего года продолжилось у побегов 2-го, 3-го и 4-го порядка (весенний тип). Растения в Варианте Н2 уходят в зиму в вегетативном состоянии, верхушечная меристема соответствует II-III этапам органогенеза, процессы индукции цветения отмечены весной следующего года, формируется весенний тип генеративных побегов.

В варианте A1 растения в конце вегетации первого года жизни находились в фазе кущения, на главном побеге насчитывалось 5-6 листьев, верхушечная меристема соответствовала II этапу органогенеза. Растения второго года жизни, имели побеги 4-го и 5го порядка, количество листьев насчитывалось 18 19 шт. В конце вегетации верхушечная меристема у большинства побегов соответствовала III-IV этапам органогенеза, что соответствует переходу растений в фазу генеративного развития. Весной третьего года жизни растения продолжили развитие генеративной сферы, насчитывалось максимальное количество генеративных побегов (1056 шт./на м²). С четвертого года жизни заметно снижается активность побегообразования и урожайность образца.

Анализ полученных результатов показывает, что сроки посевов и возраст растений напрямую влияют на семенную продуктивность и урожай семян. Это подтверждает теоретический и практический опыт автора C. Yoder (2017), который рекомендует для получения на следующий год высокого урожая посев проводить не позднее середины июня [18]. При весеннем посеве наблюдается большее количество генеративных побегов и урожая семян, чем при раннелетнем посеве, что прослеживается в наших результатах (табл. 1) с первого по четвертый год плодоношения образца. Это прослеживается и по другим параметрам семенной продуктивности - числу цветков в колосках. Значительно большее количество цветков на колоске формируется в ранних посевах по сравнению с более поздними [19].

Определенный этап органогенеза характеризуется фазой развития растений. По количеству побегов растения и листьев на главном побеге можно определить этап органогенеза. Переход от вегетативного роста к репродуктивному в период индукции цветения тесно связан с фазой роста и развития растения, с общим количеством побегов и с числом развернувшихся листьев на побеге. И в меньшей степени от длительности вегетационного периода и суммы эффективных температур. IV этап органогенеза соответствует переходу растений в генеративное развитие.

При весеннем посеве максимум урожая и активность побегообразования у растений $F$. rubra отмечен на третьем году жизни, снижение наблюдается на четвертый. В течение всех лет наблюдений уро-

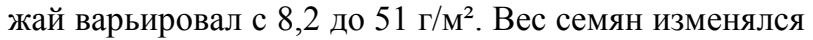
с 0,58 до 0,95 г. При раннелетнем сроке посева максимум урожая отмечен только на четвертый год, снижение на 5-й. При осеннем посеве первое плодоношение наблюдается на третьем году жизни растений и является максимальным за весь период наблюдения. T.S. Aamlid (Норвегия) [20] отмечает, что при 
изучении урожайности F. rubra при весенних и осенних вариантах посева образуется максимальное количество побегов. Объясняется это «накоплением» за период в 21 месяц, прошедших с момента всходов семян до первого урожая. О нецелесообразности попыток получить хороший урожай семян на третий год культивирования, при существующих схемах посева $F$. rubra на семена, говорят многие исследования, в частности N.A. Fairey (1996), поскольку первоначальная плотность растений увеличивается по мере уменьшения интервала между рядами [21]. Во многих семеноводческих хозяйствах приняты двухгодичные схемы использования семенников, как экономически рентабельные. Потенциальная и реальная семенная продуктивность варьирует в значительной степени. Наибольший коэффициент продуктивности наблюдается в год максимального развития злака, когда наблюдается максимальный выход семян с единицы площади, так как низкая плотность растений обеспечивает увеличенное количество побегов на единицу площади.

\section{Заключение}

Сравнительное изучение семенной продуктивности F. rubra в условиях Сибири и Казахстана показало, что существенное влияние на нее оказывают как сроки посева, так и экологические условия.

Морфологический анализ позволил увидеть влияние сроков посева и условий выращивания на развитие репродуктивных органов растений. При изучении состояния главного конуса нарастания нами было зафиксировано наступление этапа формирования соцветия.

Выявлены особенности роста и развития растений при разных сроках посева, что отразилось на реальной семенной продуктивности и урожайности. При весеннем посеве максимальный урожай семян (до 48 г/м²) можно получить на третий год жизни злака. Раннелетний посев переносит максимальный урожай (до $51 \Gamma / \mathrm{M}^{2}$ ) на четвертый год жизни растений. При осеннем посеве первое плодоношение растений происходит только на третий год жизни и выражается в максимальном количестве генеративных

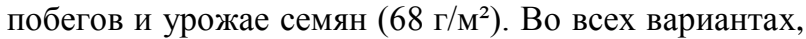
после получения максимального урожая, на следующий год наблюдается резкое снижение показателей, что согласуется с результатами N.A. Fairey [21] о двухгодичном использовании семенников.

Образцы Festuca rubra - К-0026 (Алмата) и дикорастущая форма (Новосибирск), прошедшие испытание в разных условиях, рекомендуются семеноводческим хозяйствам для создания семенного фонда и практического использования в культуре.

\section{Список литературы:}

1. Цвелев Н.Н. Злаки СССР. Л.: Наука. Ленингр. отд-ние, 1976.788 с.

2. Зуева Г.А. Влияние экологических условий на семенную продуктивность некоторых представителей дернообразующих злаков // Сибирский вестник сельскохозяйственной науки. 2009. № 1. С. 36-42.

3. Турухан О.В. Биологические особенности создания агрофитоценозов овсяницы красной (Festuca rubra L.) // Вестник Тамбовского университета. Cерия: естественные и технические науки. 2014. Т. 19, вып. 5. С. 1589-1592.

4. Gisluma R., Halekohb U., Boelta B. Seed yield responses to climate // Proceedings of the Seventh Interna- tional Herbage Seed Conference Dallas / eds. G.R. Smith, G.W. Evers, L.R. Nelson. 2010 April 11-13. Texas, 2010. P. 177.

5. Мальцев А.В., Дроздов А.В. Осенняя индукция цветения овсяницы красной // Онтогенез травянистых поликарпических растений: сборник научных трудов. Свердловск: УрГУ, 1986. С. 122-129.

6. Havstad L.T., Aamlid T.S., Heide O.M., Junttila $\mathrm{O}$. Transfer of flower induction stimuli to non-exposed tillers in a selection of temperate grasses // Acta Agriculturae Scandinavica. Section B: Soil and Plant Science. 2004. Vol. 54. P. 23-30.

7. Воронина Л.В., Гриценко А.Г. Климат и экология Новосибирской области: монография. Новосибирск: СГГА, 2011. 227 с.

8. Методика фенологических наблюдений в ботанических садах СССР. М.: Наука, 1975. 18 с.

9. Сигалов Б.Я. Результаты исследований по созданию и содержанию газонов // Бюл. ГБС АН СССР. 1971. Вып. 81. С. 77-82.

10. Лаптев А.А. Газоны. Киев: Наук. Думка, 1983. $176 \mathrm{c}$.

11. Куперман Ф.М. Основные этапы развития и роста злаков // Этапы формирования органов плодоношения злаков. Т. 1. М.: Изд-во МГУ, 1955. С. 26-33.

12. Ржанова Е.И. Формирование генеративных органов у тимофеевки луговой в зависимости от продолжительности освещения и качества света // Доклады АН СССР. 1951. С. 80.

13. Ржанова Е.И. Морфогенез зерновых бобовых растений трибы виковых // Экспериментальный морфогенез цветковых растений. М., 1972. С. 56-91.

14. Васько П.П., Чекель Е.И. Семеноводство многолетних трав: посев, уход, уборка // Современные ресурсосберегающие технологии производства растениеводческой продукции в Беларуси: сборник научных материалов НПЦ НАН Беларуси по земледелию. Минск: ИВЦ Минфина, 2007. С. 282-291.

15. Левина Р.Е. Репродуктивная биология семенных растений: Обзор проблем. М.: Наука, 1981. 96 с.

16. Доспехов Б.А. Методика полевого опыта (с основами статистической обработки результатов исследований). 5-е изд., доп. и перераб. М.: Агропромиздат, 1985. $351 \mathrm{c.}$

17. Рязанова Л.Г., Проворченко А.В., Горбунов И.В. Основы статистического анализа результатов исследований в садоводстве: уч.-метод. пособие. Краснодар: КубГАУ, 2013. 61 с.

18. Yoder C. Creeping Red Fescue Seed Production in the Peace River Region // Alberta Agriculture Food and Rural Development. 2017. P. 19.

19. Abel S., Gislum R., Boelt B. Path and correlation analysis of perennial ryegrass (Lolium perenne L.) seed yield components // Journal of Agronomy and Crop Science. 2017. Vol. 203. P. 338-344. DOI: 10.1111/jac. 12202.

20. Aamlid T.S. Undersowing creeping red fescue (Festuca rubra var rubra) for seed production in winter and spring wheat cover crops // Seed Production and Management: proceeding 18th International Grass Congress. Ses. 25. 1997. P. 3-4.

21. Fairey N.A., Lefkovitch L.P. Crop density and seed production of creeping red fescue (Festuca rubra L. var. rubra) // Canadian Journal of Plant Science. 1996. Vol. 76 (2). P. 291-298. 


\title{
REPRODUCTIVE FEATURES OF FESTUCA RUBRA L. IN DIFFERENT ENVIRONMENTAL CONDITIONS
}

(C) 2018

\author{
Zueva Galina Aleksandrovna, candidate of biological sciences, \\ senior researcher of Ornamental Plants Introduction Laboratory \\ Central Siberian Botanical Garden of Siberian Branch of Russian Academy of Sciences \\ (Novosibirsk, Russian Federation) \\ Khusainova Irina Viktorovna, researcher of Laboratory of Introduction \\ Institute of Botany and Phytointroduction (Almaty, Republic of Kazakhstan)
}

\begin{abstract}
The paper presents comparative results of Festuca rubra L. seed productivity study in Siberia and Kazakhstan. The authors consider the influence of ecological conditions on the organo-educational process of the species. The authors reveal specific features of plants growth and development at different terms of seeding in different ecological conditions. In the first year of vegetation, plants in all variants undergo two phenological phases - shoots and tillering. Different planting dates make significant changes in the reproductive capacity of plants. In spring plants sowing apical meristem at the end of the growing season corresponds to the IV stage of organogenesis. The following year in spring, shoots of the $2^{\text {nd }}, 3^{\text {rd }}$ and $4^{\text {th }}$ orders also become generative. An optimal method of Festuca rubra growing with maximum parameters of seed productivity was determined. It was found out that during spring sowing the maximum yield of seeds (up to $48 \mathrm{~g} / \mathrm{m}^{2}$ ) can be obtained for the $3^{\text {rd }}$ year of life of the cereal. For the $4^{\text {th }}$ year there is a slight decrease $\left(45,4 \mathrm{~g} / \mathrm{m}^{2}\right)$. With the early sowing date - the maximum yield (up to $51 \mathrm{~g} / \mathrm{m}^{2}$ ) was obtained only for the $4^{\text {th }}$ year of plant life and a further decrease is observed. During autumn sowing, the first fructification of cereals occurs only in the $3^{\text {rd }}$ year of life and is expressed in the maximum number of shoots and the yield of seeds $\left(68 \mathrm{~g} / \mathrm{m}^{2}\right)$. Further sharp decrease in such indicators as generative shoots and yields indicates the inexpediency of further preservation of the testes.

Keywords: Festuca rubra; lawn plant; ecological and biological features; climatic conditions; laboratory and field germination; reproductive capacity; organogenesis; seed productivity; harvest; environmental conditions; induction of flowering; seed production; ways of growing; Novosibirsk city; Almaty city.
\end{abstract}

УДК 581.92

DOI 10.24411/2309-4370-2018-14106

Статья поступила в редакцию 01.07.2018

\section{ОСНОВНЫЕ ЧЕРТЫ СЕМЕЙСТВЕННОГО СПЕКТРА АДВЕНТИВНОЙ ФРАКЦИИ ФЛОРЫ САМАРО-УЛЬЯНОВСКОГО ПОВОЛЖЬЯ}

(C) 2018

Иванова Анастасия Викторовна, кандидат биологических наук, научный сотрудник лаборатории проблем фиторазнообразия

Костина Наталья Викторовна, доктор биологических наук,

заведующий лабораторией моделирования и управления экосистемами

Институт экологии Волжского бассейна РАН (г. Тольятти, Самарская область, Российская Федераџия)

Лысенко Татьяна Михайловна, доктор биологических наук, ведущий научный сотрудник

лаборатории общей геоботаники; ведущий научный сотрудник лаборатории проблем фиторазнообразия

Ботанический институт им. В.Л. Комарова РАН (г. Санкт-Петербург, Российская Федераичи); Институт экологии Волжского бассейна РАН (г. Тольятти, Самарская область, Российская Федерация)

Аннотация. Изучение адвентивной фракции флоры представляет собой отдельное направление флористических исследований. Изучаются общие закономерности последствий внедрения адвентивных видов, их распространение по территории. Нередко при изучении адвентивной фракции анализируется семейственный спектр. В статье рассматривается адвентивная фракция флоры территории Самаро-Ульяновского Поволжья, которая расположена в пределах двух природных зон - лесостепной и степной, четырех физико-географических провинций и 15 районов. Каждое физико-географическое подразделение характеризуется своими особенностями рельефа, геологического строения, почв, растительности и местных климатических условий. В семейственном спектре адвентивной фракции Самаро-Ульяновского Поволжья возможно выделить семейства, играющие ведущую роль в формировании ее состава. На основании данных по адвентивным фракциям флор физико-географических провинций и районов, выделенных на изучаемой территории, можно сказать, что первые четыре места в спектре занимают семейства Asteraceae, Poaceae, Brassicaceae и Chenopodiaceae. Перечень этих четырех ведущих семейств адвентивной фракции флоры остается неизменным, однако их порядок может быть различен. Вероятно, различия природных условий изученных территорий отражаются именно в порядке расположения ведущих семейств, так как состав их не изменяется. Изменение состава ведущей четверки семейственного спектра можно наблюдать в масштабах больших территорий, сравнивая спектры адвентивных фракций Ивановской, Тверской, Астраханской областей, а также других административных подразделений. Флоры различных физико-географических подразделений Самаро-Ульяновского Поволжья, несмотря на принадлежность к различным природным зонам, имеют сходные семейственные спектры адвентивных фракций. Отличаются они лишь присутствием одного-двух семейств. Например, среди ведущих семейств адвентов не во всех случаях оказались Rosaceae, Onagraceae и Rubiaceae.

Ключевые слова: адвентивная фракция флоры; семейственный спектр флоры; ведущие семейства; Самаро-Ульяновское Поволжье; физико-географические подразделения. 